\title{
Butyrate Modulates Inflammation in Chondrocytes via GPR43 Receptor
}

\author{
Claudio Pirozzia ${ }^{a, b}$ Vera Francisco ${ }^{a} \quad$ Francesca Di Guida ${ }^{b}$ Rodolfo Gómez ${ }^{c}$ \\ Francisca Lago ${ }^{d}$ Jesus Pino ${ }^{a}$ Rosaria Melib ${ }^{b}$ Oreste Gualillo
}

aSERGAS (Servizo Galego de Saude) and IDIS (Instituto de Investigación Sanitaria de Santiago), The NEIRID Lab (Neuroendocrine Interactions in Rheumatology and Inflammatory Diseases), Research Laboratory 9, Santiago University Clinical Hospital, Santiago de Compostela, Spain, bepartment of Pharmacy. University of Naples Federico II, Naples, Italy, ' The NEIRID Group. Musculoskeletal Pathology Division. SERGAS (Servizo Galego de Saude) and IDIS (Instituto de Investigación Sanitaria de Santiago), Research Laboratory 9, Santiago University Clinical Hospital, Santiago de Compostela, dMolecular and Cellular Cardiology Laboratory. SERGAS (Servizo Galego de Saude) and IDIS (Instituto de Investigación Sanitaria de Santiago), Research Laboratory 7, Santiago University Clinical Hospital, Santiago de Compostela, Spain

\section{Key Words}

Butyrate $\bullet$ Chondrocytes • Inflammation • Chemokines • GPR43

\begin{abstract}
Background/Aims: Osteoarthritis $(\mathrm{OA})$ is a joint degenerative biomechanical disorder involving immunity, metabolic alterations, inflammation, and cartilage degradation, where chondrocytes play a pivotal role. OA has not effective pharmacological treatments and new therapeutic targets are needed. Adipokines contribute to the low-grade systemic inflammation in OA. Here, we explored novel molecular mechanisms of sodium butyrate (BuNa) in modulating inflammation and chemotaxis in chondrocytes, demonstrating the direct involvement of its $G$ protein-coupled receptor (GPR)-43. Methods: ATDC5 murine chondrocytes were stimulated with interleukin (IL)-1 $\mathrm{B}$, in the presence or not of BuNa, for $24 \mathrm{~h}$. RT-PCR and Western blot analysis was performed to evaluate the expression of inflammatory mediators and structural proteins. Results: Butyrate reduced the expression of canonic proinflammatory mediators (Nos2, COX-2, IL-6), pro-inflammatory adipokines (lipocalin-2 and nesfatin-1) and adhesion molecule (VCAM-1 and ICAM-1) in IL-1 $\beta$-stimulated chondrocytes, inhibiting several inflammatory signalling pathways (NFKB, MAPKinase, AMPK- $\alpha$, PI3K/Akt). Butyrate also reduced metalloproteinase production and limited the loss of type II collagen in IL-1 $\beta$-inflamed chondrocytes. The chemoattractant effect of butyrate, after different inflammatory challenges, was revealed by increased annexin (AnxA) 1 levels and chemokines expression. The chemoattractant and anti-inflammatory activities of butyrate were completely
\end{abstract}


blunted by GPR43 silencing using RNA interference. Conclusion: Taken together, our data suggest the potential application of sodium butyrate as a novel candidate in a multi-target approach for the treatment of chondrocyte inflammation and cartilage degenerative process.

\section{Introduction}

Osteoarthritis $(\mathrm{OA})$ is the most common rheumatic disease and a major cause of pain and chronic disability in adults. OA development is strongly influenced by ageing, obesity and biomechanical injury [1]. Although OA involves whole joint structures and is characterized by a progressive degradation of the articular cartilage, the pivotal role of chondrocytes is related not only to the impaired production/responsiveness to catabolic, anabolic and inflammatory stimuli but also to the failed repair of cartilage matrix damage [2].

IL-1 $\beta$ is a cytokine that plays a pivotal role in the inflammatory response and catabolic events in chondrocytes $[3,4]$ eliciting the synthesis of prostaglandins by cyclooxygenases (COXs) [5] and the activation of several cytoplasmic protein kinases (MAPK, ERK 1/2 and p38 kinase) [6]. The activation of these kinases drives specific signalling pathways that increase the DNA binding activity of NF- $\kappa \mathrm{B}$ and AP-1, both factors implicated in the transcription of pro-inflammatory genes, such as COX-2 and Nos2 [7]. Additionally, these factors also promote the transcription of catabolic genes such as matrix metalloproteinases (MMPs), which are involved in $\mathrm{OA}$-associated degradative process [8].

The use of non-steroidal anti-inflammatory drugs (NSAIDs) has been the major pharmacologic approach to treating the symptoms of degenerative and inflammatory arthropathies [9], even though these drugs fail to modify the degenerative processes. Although considerable progress has been made in the development of novel pharmacological strategies, such as the MMP inhibitors [10], no clinically effective inhibitor exists to date. The search for alternative and/or complementary anti-inflammatory agents that might counteract the joint degenerative processes and the resulting injury is thus of paramount importance.

The identification of novel therapeutic properties of active compounds targeting multiple pathways could provide an alternative to conventional treatment of OA [11]. Toward this goal, recent studies suggest that natural products that are rich in antioxidant and antiinflammatory compounds might contribute to the prevention of inflammatory diseases such as $\mathrm{OA}[12]$.

Butyrate is a short-chain fatty acid (SCFA), mainly produced from undigested fibres metabolically fermented in the large intestine, and is considered the major energy source for colonocytes, maintaining intestinal homeostasis and functions [13].

Recent experimental evidence suggested different therapeutic applications for butyrate, including its ability to treat metabolic and inflammatory diseases [14, 15]. Butyrate effects include epigenetic modifications due to its inhibitory effects on histone deacetylases (HDAC), inhibition of NF- $\kappa B$ signalling [16], and the direct agonism on the SCFA G-protein coupled receptors, GPR41 and GPR43 [17]. Butyrate is also involved in the activation of peroxisome proliferator-activated receptors (PPARs), a class of nuclear receptors that modulate inflammation, pain, and nociception [18]. Clinical trials in patients with inflammatory bowel diseases evidenced the anti-inflammatory effect of butyrate, by suppressing mucosal inflammation and NF-kB activation in lamina propria macrophages [19, 20]. Finally, immunomodulatory effects of butyrate on neutrophil chemotaxis, mediated by its receptors on immune cells, have been also described [21,22].

In the past, some beneficial effects of butyrate have been determined in chondrocytes $[5,23]$, but the complete mechanism of its anti-inflammatory activity was overlooked. The aim of this study was to evaluate novel molecular mechanisms of butyrate as a modulator of inflammation and regenerative process in chondrocytes. 


\section{Cellular Physiology Cell Physiol Biochem 2018;51:228-243

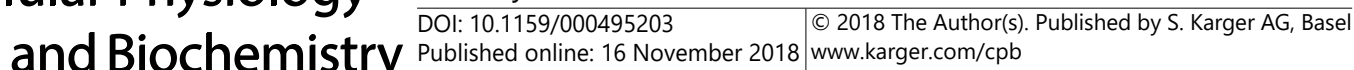 \\ Pirozzi et al.: Butyrate Effect on Inflamed Chondrocytes}

\section{Materials and Methods}

\section{Cell culture}

The murine chondrogenic cell line ATDC5 (purchased from RIKEN Cell Bank, Tsukuba, Japan) was cultured as previously [7], and allowed to differentiate into mature chondrocytes [24]. All reagents were purchased from Sigma (Missouri, USA) unless otherwise specified.

\section{Cell viability and nitrite assay}

Cell metabolic activity was examined using a colorimetric assay based on the MTT labeling reagent. Cells were seeded in 96-well plates (8, 000 cells/well) and pre-treated with $250 \mu \mathrm{M} \mathrm{BuNa}$ (Sigma-Aldrich) for 1 hour; then, IL-1 $\beta(0.5 \mathrm{ng} / \mathrm{ml})$ was added for $24 \mathrm{~h}$. Assays were performed according to the instructions and protocol provided by the manufacturer (Sigma-Aldrich). Spectrophotometrical absorbance was measured using a microtiter ELISA reader at $550 \mathrm{~nm}$ (Multiskan EX, Termo Labsystem, Barcelona, Spain).

Nitrite accumulation was measured in the culture medium by Griess reaction. Briefly, $100 \mu \mathrm{l}$ of cell culture medium was mixed with $100 \mu \mathrm{l}$ of Griess reagent (equal volumes of $1 \%$ [weight/volume] sulfanilamide in $5 \%$ [volume/volume] phosphoric acid and $0.1 \%[\mathrm{w} / \mathrm{v}]$ naphtylethylenediamine $\mathrm{HCl}$ ), incubated at room temperature for 10 minutes, and then the absorbance at $550 \mathrm{~nm}$ was measured in a microplate reader (Titertek Multiscan; Labsystems, Helsinki, Finland). Fresh culture medium was used as blank in all the experiments. The amount of nitrite in the samples (in $\mu \mathrm{M}$ ) was calculated from a sodium nitrite standard curve freshly prepared in culture medium.

\section{Western blot analysis}

Cells were seeded in P6 multiwell plates at a density of $10^{6}$ cells/well and then incubated overnight in serum-free conditions. To determine Nos2, VCAM-1, and lipocalin-2 (LCN2) protein expression, ATDC5 cells were pre-treated with $250 \mu \mathrm{M}$ BuNa (Sigma-Aldrich) for 1 hour; then, IL-1 $(0.5 \mathrm{ng} / \mathrm{ml})$ was added for $24 \mathrm{~h}$, the time selected for optimal observation according to our time-course experiments. To evaluate $\mathrm{Nf \kappa B} \mathrm{p} 65$ translocation and IкB- $\alpha$ degradation, the phosphorylation of ERK1/2, p38 subunit, Akt, and AMPK $\alpha$, cells were pre-treated with BuNa for 12 hours and then challenged with IL-1 $\beta$ for 15 or $30 \mathrm{~min}$. Afterward, cells were subjected to a differential lysis to obtain the nuclear and cytosolic fractions as previously described [25]. Blots were incubated with the appropriate antibodies: anti-iNOS and anti-VCAM-1 (Cell Signaling Technology, Denver, Massachusetts, USA), lipocalin-2 (R\&D Systems, Inc., Minneapolis, MN, USA), antiphospho ERK1/2, anti-ERK1/2, anti-phospho-p38 and anti-p38 (Millipore, MA, USA), anti-NFKB p65 (Santa Cruz, CA, USA), anti-IкB- $\alpha$, anti-phospho-Akt and anti-Akt, anti-phospho-AMPK $\alpha$ and anti-AMPK $\alpha$ (Cell Signaling Technology, Denver, Massachusetts, USA). Immunoblots have been visualized with Immobilon Western Detection Kit (Millipore, MA) using horseradish peroxidase labelled secondary antibody. To confirm equal loading in each sample, the membranes were stripped in stripping buffer $(100 \mathrm{mM} \beta$-mercaptoethanol, $2 \%$ SDS, $62.5 \mathrm{mM}$ Tris-HCl pH 6.7) and re-blotted with anti-GAPDH (Sigma, MO, USA) or anti-lamin- $\beta 1$ antibody (GeneTex, CA, USA). The images were captured and analyzed with an EC3 imaging system (UVP). Densitometric analyses were performed using ImageJ software (National Institutes of Health, Bethesda, MD, USA).

RNA isolation and Real-Time PCR analysis

RNA was extracted using a NucleoSpin kit, according to the instructions and protocol provided by the manufacturer. For relative quantification, we performed an RT reaction with a First Strand Kit from SABiosciences. Next, real-time PCR was performed with an SABiosciences Master Mix and specific RT ${ }^{2}$ qPCR primers, as reported in Table 1. Results of comparative Real-Time PCR were analyzed with MxPro version 4 software (Stratagene, La Jolla, CA).

Table 1. Real-Time PCR Primer Sequence

\begin{tabular}{lcc}
\hline Target gene & Bp & Accession Number \\
\hline Nos2 & 122 & NM_010927 \\
Ptgs2 & 135 & NM_011198.3 \\
Il-6 & 178 & NM_031168.1 \\
Vcam-1 & 146 & NM_011693.3 \\
Icam-1 & 122 & NM_000201.2 \\
NUCB2 & & NM_008491.1 \\
MMP13 & 88 & NM_008607 \\
Col2a1 & 138 & NM_031163.3 \\
Ccl3 & 112 & NM_011337.2 \\
Cx3cl1 & 113 & NM_009142.3 \\
AnxA1 & 70 & NM_008084.2 \\
Gapdh & 140 & NM_017008.4 \\
\hline
\end{tabular}




\section{Cellular Physiology Cell Physiol Biochem 2018;51:228-243 \begin{tabular}{ll|l} 
and Biochemistry & $\begin{array}{l}\text { DOI: } 10.1159 / 000495203 \\
\text { Published online: 16 November } 2018\end{array}$ & $\begin{array}{l}\text { (c) } 2018 \text { The Author(s). Published by S. Karger AG, Basel } \\
\text { www.karger.com/cpb }\end{array}$
\end{tabular} \\ Pirozzi et al.: Butyrate Effect on Inflamed Chondrocytes}

siRNA-mediated gene silencing of GPR43 receptor

In order to silence GPR43 gene, we used the siRNA that targets GPR43 receptor (siGpr43, Integrated DNA Technologies, USA) and the siRNA negative control, that does not target any known sequence. Transfection with 10nM of siRNA duplex was performed using the cationic lipid siLentFect (BioRad, CA, USA) according to the manufacturer's recommendations. Cells were transfected for $48 \mathrm{~h}$ and then they were stimulated with $0.5 \mathrm{ng} / \mathrm{ml}$ of IL1 $\beta$ in the presence or not of $250 \mu \mathrm{M}$ BuNa for $24 \mathrm{~h}$.

\section{Statistical analysis}

Data are reported as mean \pm S.E.M. values of independent experiments, which were done at least three times, each time with three or more independent observations. Statistical analysis was performed by analysis of variance test, and multiple comparisons were made by Bonferroni's test. Data sets have been tested for normality by Shapiro-Wilks test (all the data sets passed this test). Statistical significance was set at $\mathrm{P}<0.05$.

\section{Results}

Butyrate reduces pro-inflammatory mediators and adipokines in IL-1 $\beta$-stimulated chondrocytes

Butyrate concentration at $250 \mu \mathrm{M}$ was chosen based on data obtained on cell viability and on its efficacy in reducing IL1 $\beta$-stimulated nitrite production (Fig. 1A and Fig. 1B, respectively).

As shown in Fig. 2, the anti-inflammatory effect of butyrate on IL-1 $\beta$-induced Nos2 synthase, Ptgs2, Il6 mRNA expression was analysed in ATDC5 chondrogenic cells. Under basal conditions, the mRNA levels of all these pro-inflammatory mediators were undetectable. IL-1 $\beta$ stimulation of ATDC5 cells induced a significant increase of all these genes.

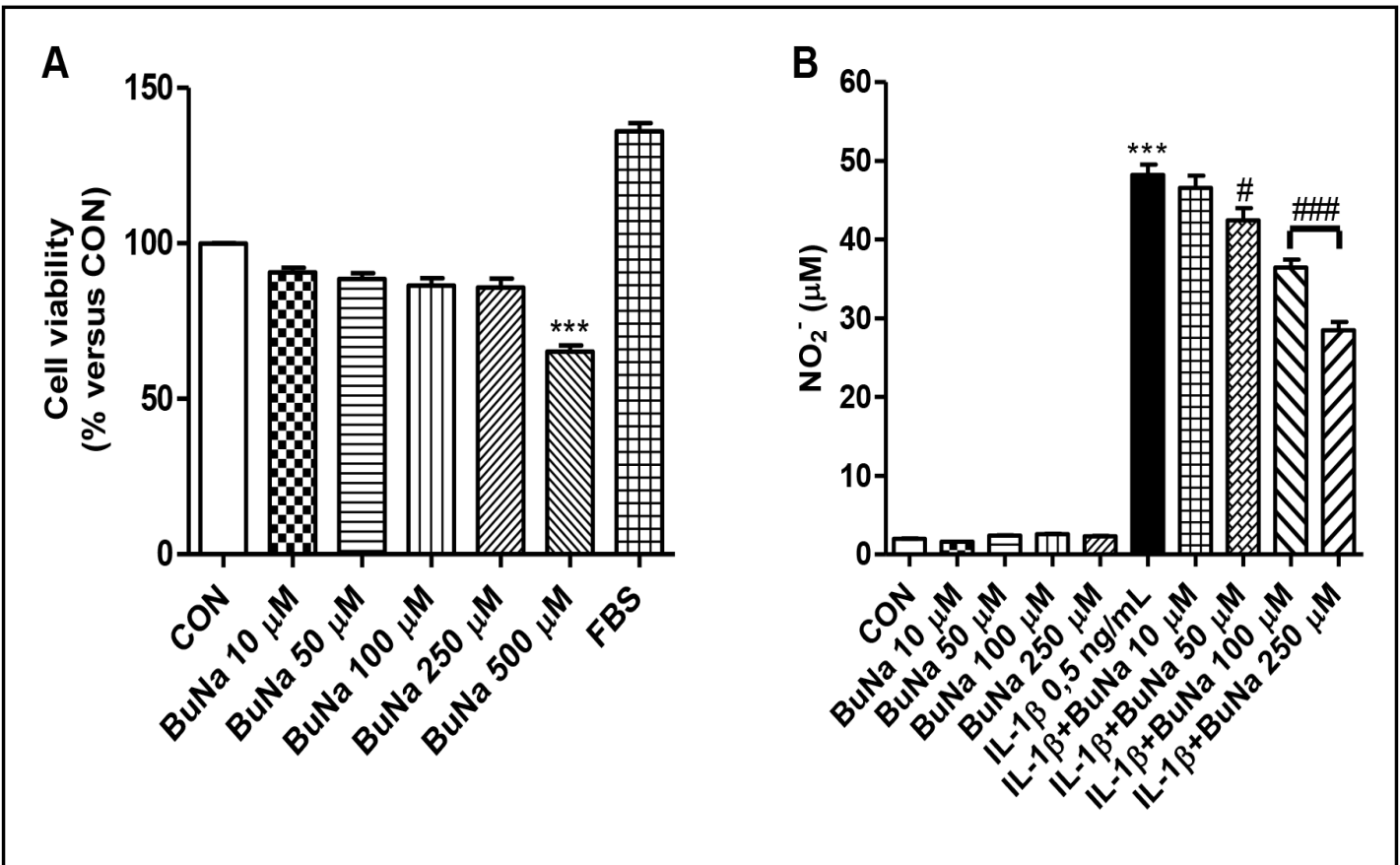

Fig. 1. Cell viability assay and nitrite accumulation. The treatment with $\mathrm{BuNa}(250 \mu \mathrm{M})$ markedly decreased IL-1ß-induced nitrite amount (B) in a dose-dependent manner but not affected cell viability (A). Data are presented as means \pm S.E.M. of 3 different experiments. ${ }^{* * *} \mathrm{P}<0.001$ vs. CON; \# $\mathrm{P}<0.01$ and \#\#\# $\mathrm{P}<0.001$ vs. IL-1 $\beta$. 


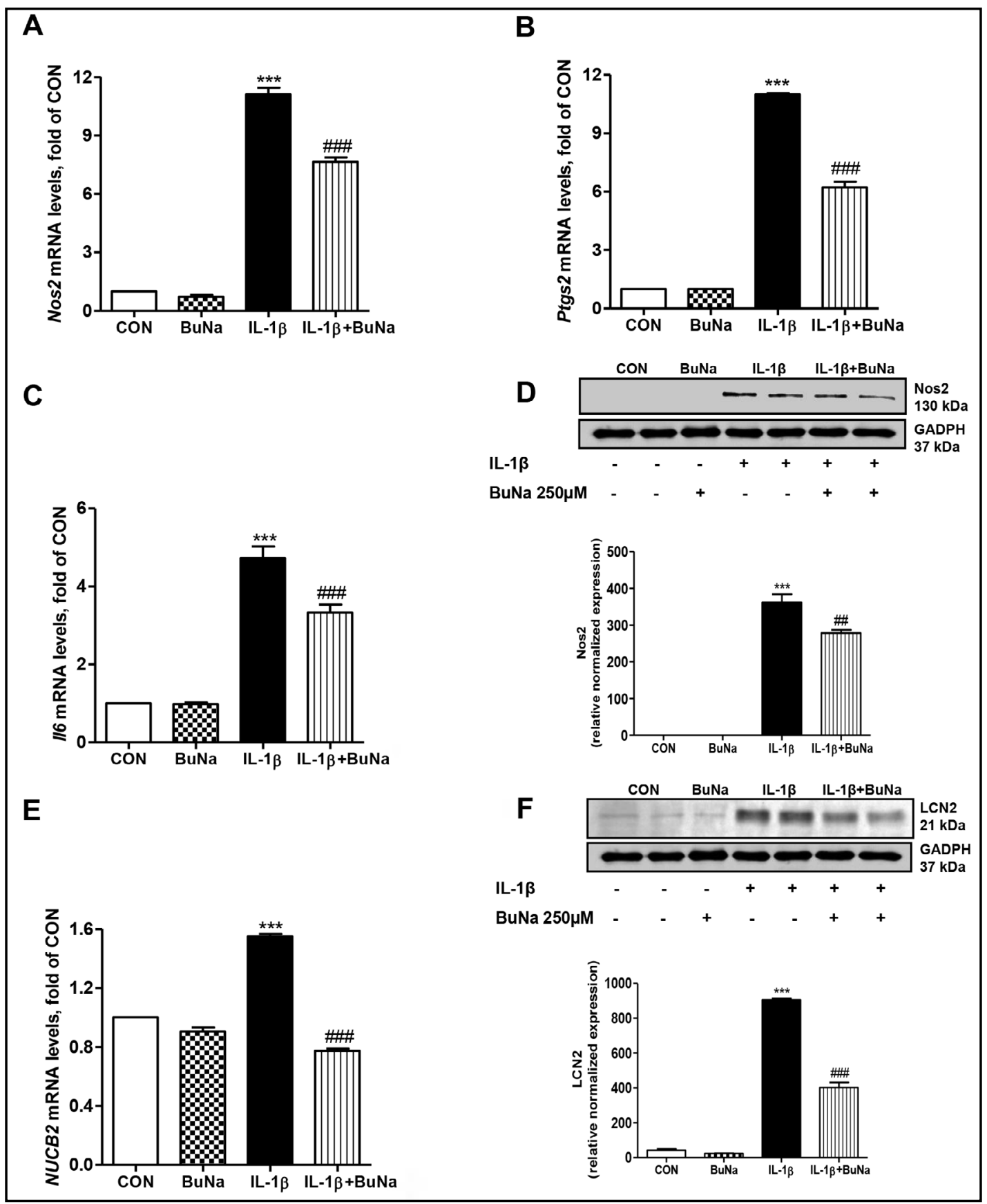

Fig. 2. Butyrate reduces inflammatory mediators and adipokines in undifferentiated ATDC5 chondrocytes stimulated by IL-1 $\beta$. IL-1 $\beta$ stimulation induced a significant increase of Nos2 (A), Ptgs2 (B), Il6 (C) mRNAs and iNOS (D) protein expression in undifferentiated chondrocytes. The mRNA levels of NUCB2 (E) and the expression of LCN2 (F) was also evaluated. Butyrate $(250 \mu \mathrm{M})$ significantly suppressed all inflammatory parameters. Real Time and Western blot data are presented as means \pm standard error of 3 different experiments. ${ }^{* * *} \mathrm{P}<0.001$ vs. CON; \#\# $\mathrm{P}<0.01$, and \#\#\# $\mathrm{P}<0.001$ vs. IL-1 $\beta$. 
Butyrate at $250 \mu \mathrm{M}$ was able to markedly suppress this induction, suggesting that its anti-inflammatory effect was at the transcriptional level (Fig. 2A-C), also confirmed by Nos2 Western Blot analysis (Fig. 2D).

For completeness, we also examined protein and mRNA expression of two relevant adipokines (LCN2 and NUCB2) involved in the regulation of inflammatory response elicited by IL-1 $\beta$ in chondrocytes. As shown in Fig. 2E and Fig. 2F, BuNa was able to significantly decrease NUCB2 mRNA levels and the expression of lipocalin-2.

\section{Butyrate reduces adhesion molecule} expression

The vascular cell adhesion molecule (VCAM)-1 and intercellular adhesion molecule (ICAM)-1 mediate the adhesion of lymphocytes, monocytes, eosinophils, and basophils to vascular endothelium and may play a role in the development of a rheumatic disease [26]. As shown in Fig. $3 \mathrm{~A}$ and Fig. 3B, IL-1 $\beta$ was able to strongly induce both Icam1 and Vcam1 mRNA expression. Butyrate significantly decreased the expression of both adhesion molecules mRNAs induced by IL-1 $\beta$. This effect was also observed in terms of VCAM1 protein expression as shown in Fig. 3C.

\section{Effect of butyrate on pro-inflammatory signalling pathways}

In response to inflammatory stimuli, the p65 subunit of $\mathrm{Nf} \kappa \mathrm{B}$ is activated and translocated into the nucleus whereas I $\kappa \mathrm{B}-\alpha$ is degraded at the cytoplasm. In our experiments, after IL-1 $\beta$ stimulation for 15 30 minutes, the activation of the $\mathrm{p} 65$ subunit and consequently I $\mathrm{KB}-\alpha$ degradation was observed. Butyrate, on IL-1 $\beta$-stimulated ATDC5 cells, significantly reduced NFKB p65 expression and consistently increased IкB- $\alpha$ (Fig. 4A and Fig. 4B).

Butyrate also significantly decreased IL-1 $\beta$-induced phosphorylation of ERK1/2 and p38 kinases suggesting that its anti-inflammatory effect involved the inactivation of the MAP-kinase signalling pathway (Fig. 4C and Fig. 4D).

It is well known that IL-1 $\beta$ induces the phosphorylation and activation of AMP-activated protein kinase (AMPK)- $\alpha$, an enzyme that works as a metabolic switcher, modulating cell homeostasis. As shown in Fig. 4E, the phosphorylation of AMPKa was significantly increased

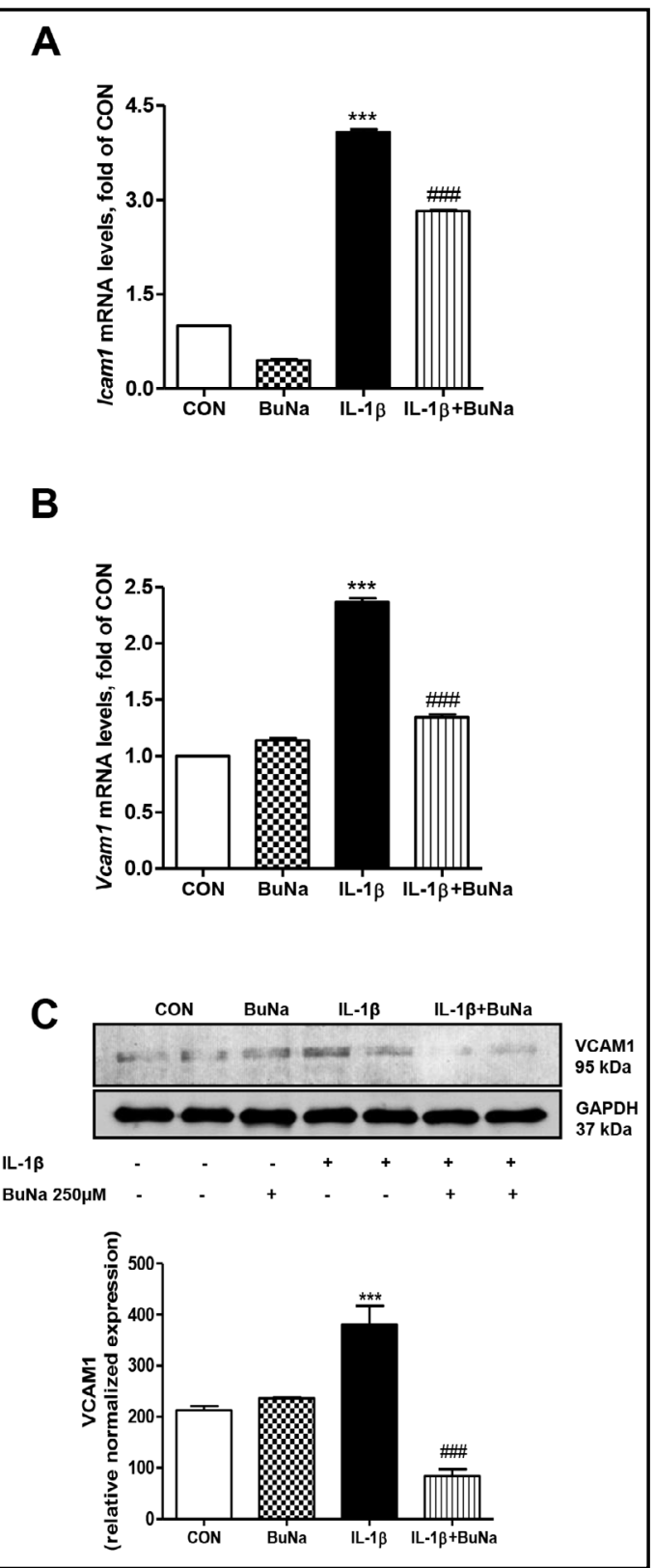

Fig. 3. Effect of butyrate on expression of VCAM1 and ICAM- 1 after IL- $1 \beta$ stimulation. Upon IL- $1 \beta$ stimulation, mRNA levels of Icam1 (A) and Vcam1 (B) and the protein expression of VCAM-1 (C) were measured. BuNa $(250 \mu \mathrm{M})$ significantly reduced these levels. Real-Time and Western blot data are presented as means \pm standard error of 3 different experiments. ${ }^{* * *} \mathrm{P}<0.001$ vs. CON; \#\#\# $\mathrm{P}<0.001$ vs. IL-1 $\beta$. 


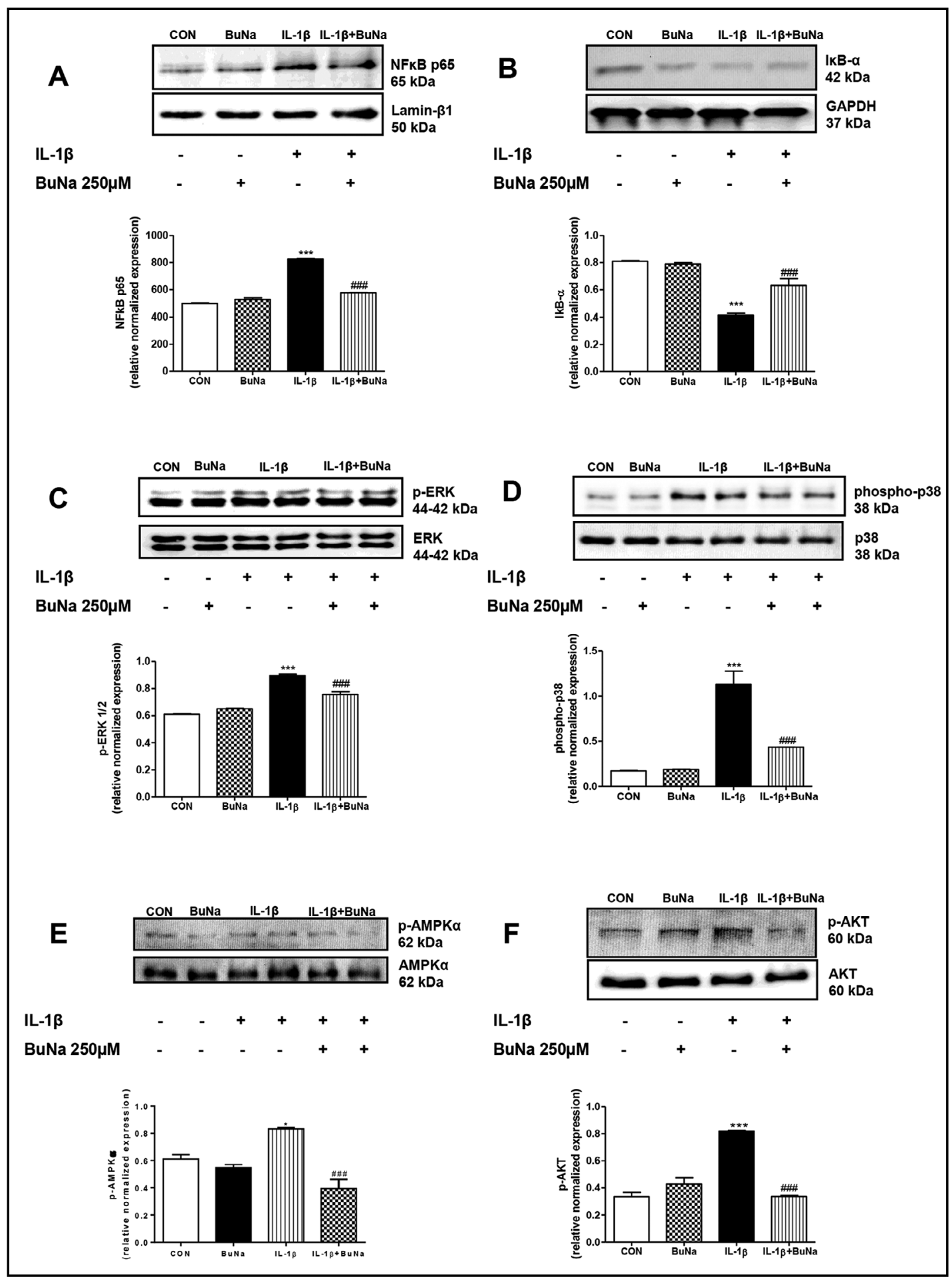

Fig. 4. Effect of butyrate on pro-inflammatory signalling pathways in ATDC5 cells. After IL-1 $\beta$ stimulation for

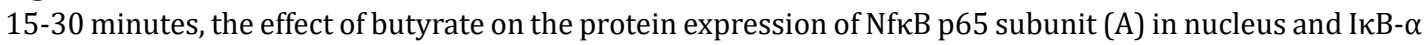
(B) in cytoplasm was evaluated. The anti-inflammatory activity of BuNa $(250 \mu \mathrm{M})$ on the phosphorylation of p44/42 MAPK (or ERK 44/42) (C) and of p38 subunit (D), was shown. BuNa treatment also decreased the phosphorylation of AMPK $\alpha(E)$ and of Akt (F), both altered by IL-1 $\beta$. Representative western blot data are presented as means \pm standard error of 3 different experiments. ${ }^{*} \mathrm{P}<0.01$ and ${ }^{* * *} \mathrm{P}<0.001$ vs. CON; \#\#\# $\mathrm{P}<0.001$ vs. IL- $1 \beta$. 


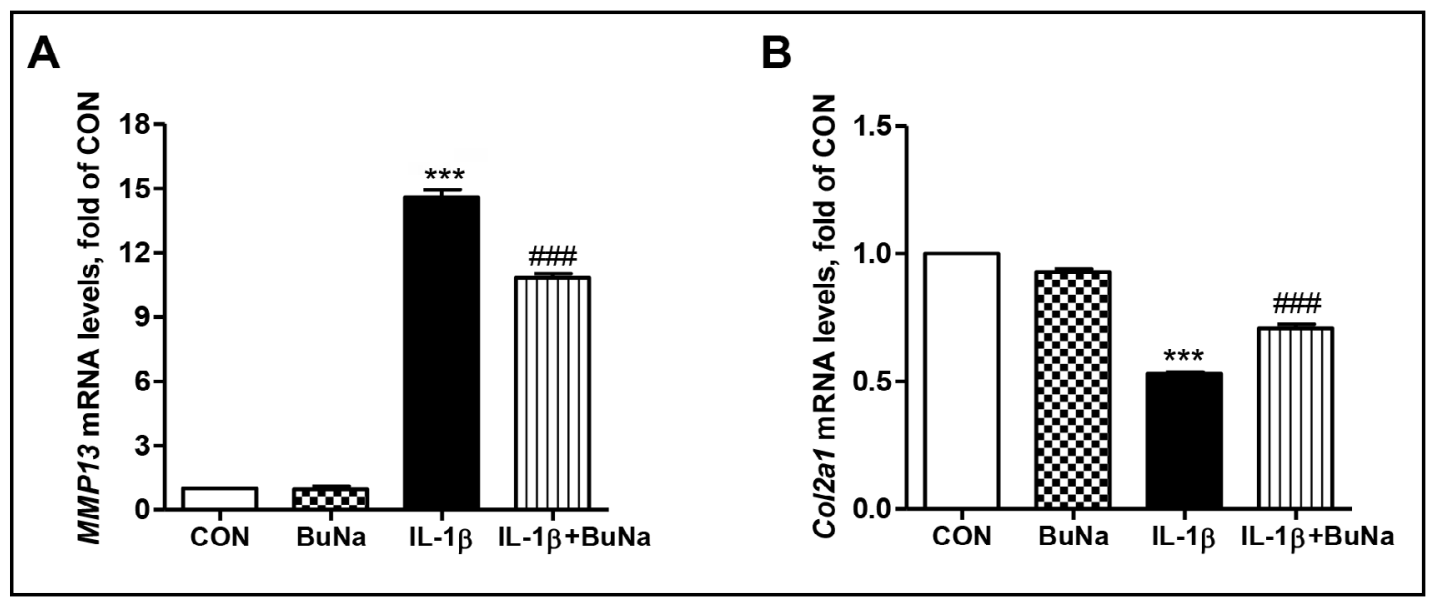

Fig. 5. Butyrate treatment modulates MMP13 and type II collagen mRNA levels. Cartilage destruction in the osteoarthritis is mediated mainly by the matrix MMPs. BuNa $(250 \mu \mathrm{M})$ resulted in (A) suppressing MMP13 mRNA expression and (B) in increasing type II collagen levels. Real-Time data are presented as means \pm standard error of 3 different experiments. ${ }^{* * *} \mathrm{P}<0.001$ vs. CON; \#\#\# $\mathrm{P}<0.001$ vs. IL-1 $\beta$.

Fig. 6. Effect of butyrate on immune response to inflammatory process induced by different inflammatory challenges. Different inflammatory stimuli, IL-1 $\beta$, LPS (1 $\mathrm{ng} / \mathrm{mL}$ ) or TNF- $\alpha(0,1 \mathrm{ng} / \mathrm{mL})$ induced neutrophils and leucocytes recruitment, (A and B) increasing mRNA expression of $\mathrm{Ccl} 3$ and (C, D and E) $\mathrm{Cx} 3 \mathrm{cl} 1$ and (F) induced the transcription of AnxA1. BuNa $(250 \mu \mathrm{M})$ showed a chemoattractant and an ti - inflam mat ory effect, further increasing mRNA expression of these genes. Real-Time data are presented as means \pm standard error of 3 different experiments. $* * * \mathrm{P}<0.001 \quad$ vs. $\mathrm{CON}$; \#\#\# $\mathrm{P}<0.001$ vs. IL-1 13 .

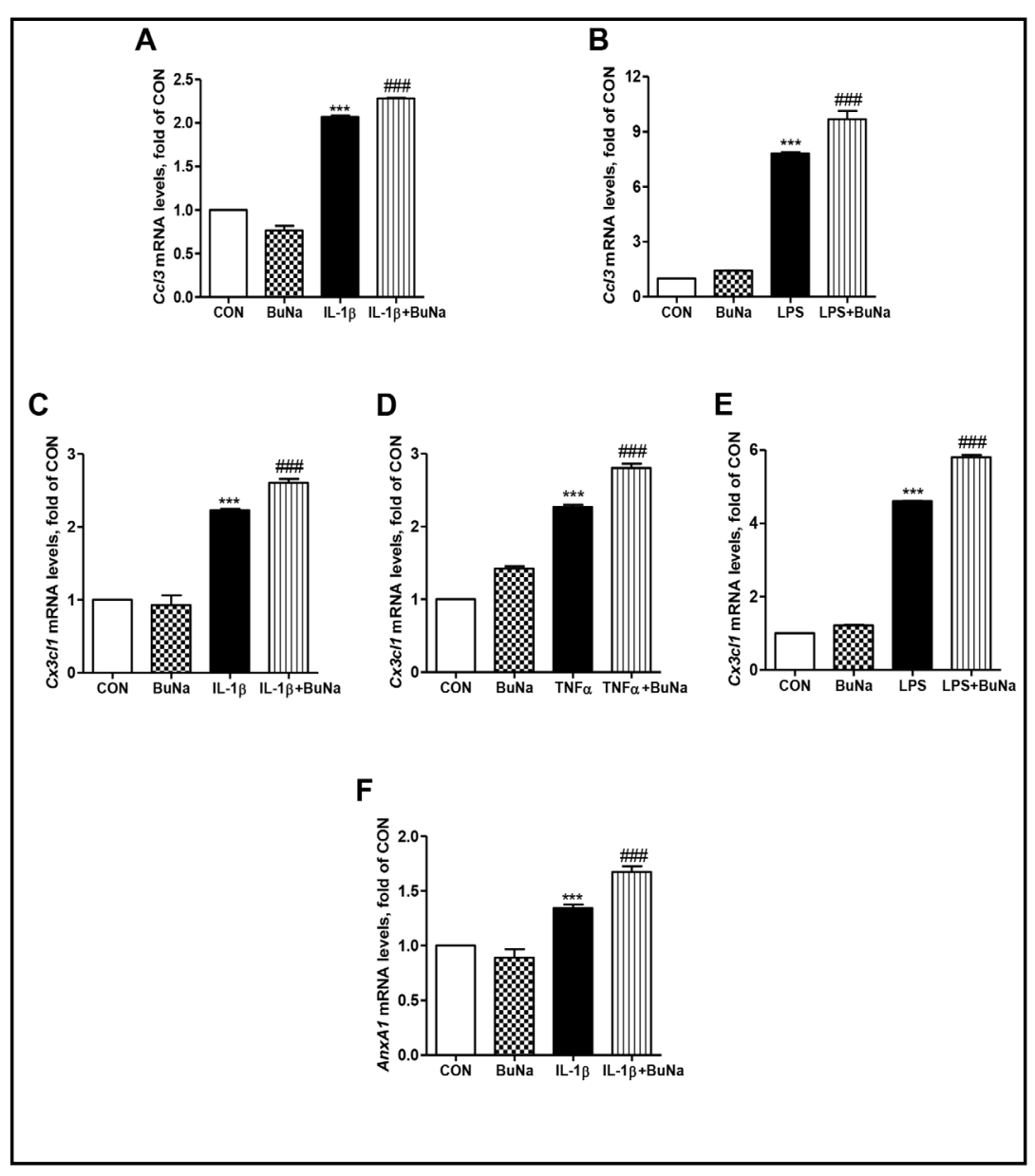




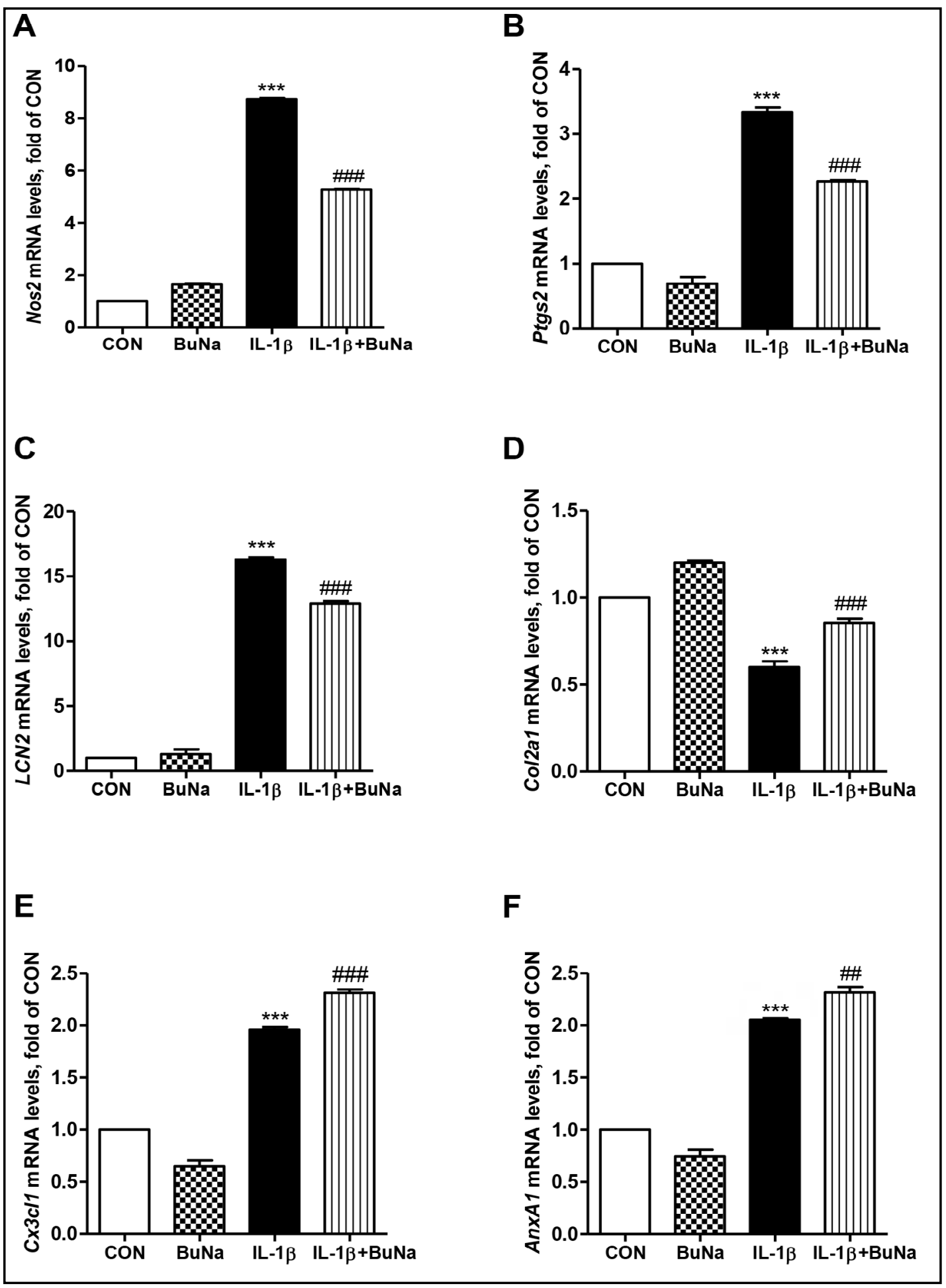

Fig. 7. Effect of butyrate on inflammatory and immune response in mature chondrocytes. After 14 days of cell differentiation, BuNa $(250 \mu \mathrm{M})$ significantly reduced inflammatory mediators, i.e. (A) Nos2 and (B) Ptgs2, and adipokines, i.e. (C) LCN2, and (D) limited the loss of Col2a1 induced by IL-1 $\beta$, confirming its anti-inflammatory activity during the differentiation. Also in mature chondrocytes, BuNa was able to play a chemoattractant role, as shown by the increased mRNA expression of (E) Cx3cl1 and (F) AnxA1. Data are

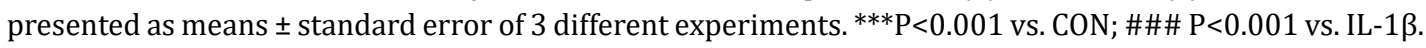




\section{Cellular Physiology Cell Physiol Biochem 2018;51:228-243 \begin{tabular}{ll|l} 
and Biochemistry & $\begin{array}{l}\text { DOl: 10.1159/000495203 } \\
\text { Published online: 16 November } 2018\end{array}$ & $\begin{array}{l}\text { O 2018 The Author(s). Published by S. Karger AG, Basel } \\
\text { ww.karger.com/cpb }\end{array}$ \\
\cline { 2 - 3 }
\end{tabular} \\ Pirozzi et al.: Butyrate Effect on Inflamed Chondrocytes}

by IL-1 $\beta$ stimulation compared with no-treated cells. On the contrary, sodium butyrate markedly reduced this phosphorylation (Fig. 4E). Similarly, butyrate strongly decreased the phosphorylation of Akt (Fig. 4F).

Effect of butyrate on MMP-13 production and type II collagen levels after inflammatory stimulation

Cartilage destruction in OA is thought to be mediated mainly by MMPs, which are responsible for collagen breakdown in the joint cartilage [27]. IL-1 $\beta$ stimulation produced a marked increase of MMP13 mRNA (Fig. 5A) and consistently a reduction of type II collagen (Col2a1) levels (Fig. 5B). However, BuNa decreased MMP13 mRNA expression and limited the reduction of Col2a1, altered by IL-1 $\beta$.

Butyrate potentiates chemokine expression after different inflammatory challenges

In ATDC5 cells, IL-1 $\beta$ has been described as a potent inducer of relevant chemokines involved in inflammatory processes and in neutrophils and leucocytes recruitment, such as Ccl3 and $C x 3 c l 1$. Similarly, IL-1 $\beta$ induces annexin-1 (AnxA1), a protein that inhibits various inflammatory events, including chemotaxis.

As shown in Fig. 6A and Fig. 6C, IL-1 $\beta$ efficiently induced the expression of $\mathrm{Ccl} 3$ and $C \times 3 c l 1$. BuNa, when used in combination with IL-1 $\beta$, further increased the chemotactic effect elicited by this cytokine. The effect of butyrate was observable even when the cells were challenged with other pro-inflammatory stimuli such as TNF $\alpha$ (Fig. 6D) or TLR4 agonists such as LPS (Fig. 6B and Fig. 6E). Notably, BuNa is also able to potentiate the transcription of AnxA1 in ATDC5 cells (Fig. 6F). All data obtained on ATDC5 chondrogenic cells were confirmed on totally differentiated ATDC5 cells, after 14 days of cell differentiation (Fig. 7A$\mathrm{F}$ ), that have been demonstrated to have the same phenotype of human mature chondrocytes $[28,29]$.

Role of GPR43 receptor in butyrate chemoattractant and anti-inflammatory activity

To clarify the potential mechanism of butyrate chemoattractant and anti-inflammatory activities, we hypothesized that these effects were modulated, totally or in part, by GPR43, the main butyrate receptor. As shown in Fig. 8A-D, gene knockdown with GPR43 siRNA completely blunted the effects of butyrate on IL-1 $\beta$-driven induction of both chemotactic factors and acute inflammatory mediators, such as Nos2 and Il6, confirming our preliminary hypothesis. 
Fig.

Chemoattractant and anti-inflammatory activities of butyrate are directly dependent on GPR43 expression. siRNA-mediated gene silencing of the GPR 43 receptor for 48 hours in ATDC5 cells. The chemoattractant effect of BuNa $(250 \mu \mathrm{M})$ on (A) Cx3cl1 and (B) AnxA1 and its antiinflammatory activity on (C) Nos2 and (D) Il6 were inhibited by GPR43 silencing. Real-Time data are presented as means \pm standard error of 3 different experiments. ${ }^{* * *} \mathrm{P}<0.001$ vs. CON; \#\#\# $\mathrm{P}<0.001$ vs. IL- $1 \beta$.
A

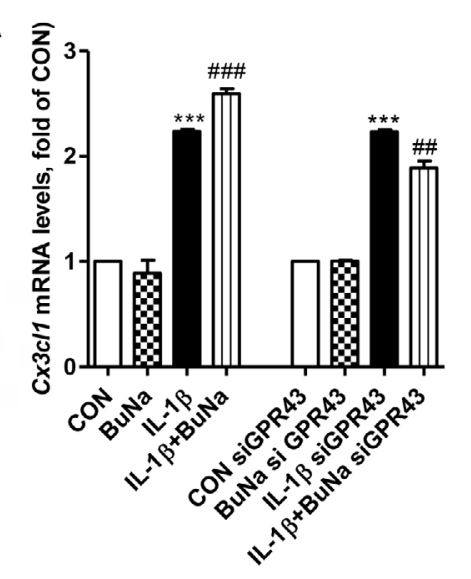

C

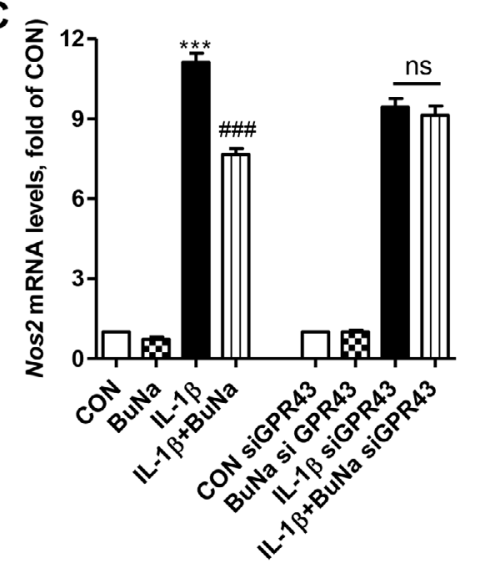

B

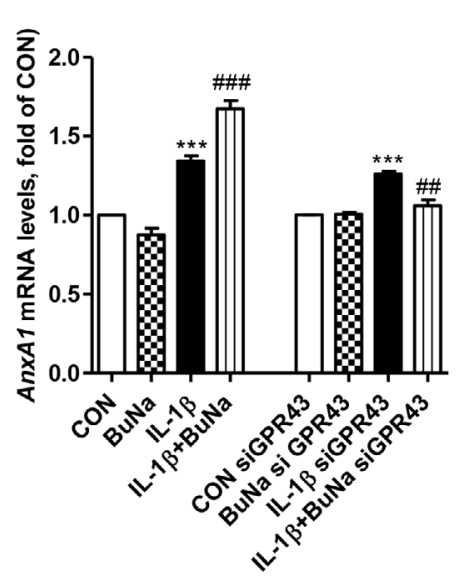

D

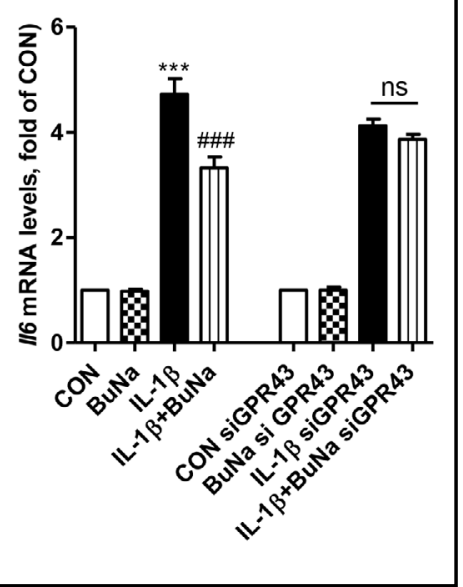

\section{Discussion}

$\mathrm{OA}$ is commonly considered a disease in which inflammatory, biomechanical, metabolic and also immune mechanisms impacted on the whole joint [30], in which the chondrocyte is regarded as the major actor [31]. Several risk factors, including obesity, ageing, and metabolic disorders promote pathogenesis and progression of this disease. Even if huge advancements have been made, in terms of identification and characterization of the molecular and cellular basis of $\mathrm{OA}$, this disease remains still orphan of effective anti-inflammatory treatments that can limit the cartilage degenerative processes and the resulting lesions.

In this study, we demonstrated that, in IL-1 $\beta$-stimulated chondrocytes, butyrate not only reduces pro-inflammatory mediators, adipokines and adhesion molecules, inhibiting several inflammatory signalling pathways, but also limits metalloproteinase production and the loss of type II collagen, highlighting the relevant role of GPR43 receptor in its antiinflammatory and chemoattractant activity. Although butyrate can modulate inflammation in intestinal and extra-intestinal diseases [14], only a little evidence showed the beneficial effect of butyrate in rheumatic disorders. Several years ago, the efficacy of butyrate in human chondrocytes was evidenced, suppressing the expression of pro-inflammatory mediators or destructive MMPs $[5,23]$, whereas more recently, the utility of butyrate treatment on acute gouty arthritis has been assessed [32]. Nevertheless, the mechanism/s by which butyrate might exert its beneficial effect in the treatment of $\mathrm{OA}$, and related disorders, is still elusive and need further investigations. 


\section{Cellular Physiology Cell Physiol Biochem 2018;51:228-243

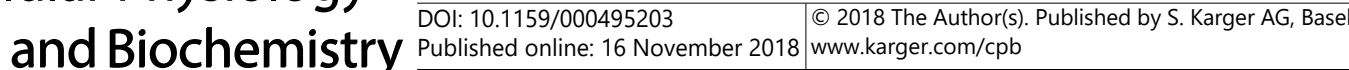 \\ Pirozzi et al.: Butyrate Effect on Inflamed Chondrocytes}

There is a bulk of evidence pointing to the relevance of inflammation in the development and progression of OA [2]. This relevance has been supported through the association of joint effusion with joint pain [33] and the significant production of several pro-inflammatory mediators [34]. In particular, IL-1 $\beta$ plays a central role in the pathophysiology of OA [3]. In fact, IL-1 $\beta$ induces a cascade of inflammatory and catabolic events in chondrocytes, including the synthesis of prostaglandin E2 (PGE2) and NO [5]. In our experimental conditions, chondrocyte stimulation with this cytokine showed increased nitrite accumulation and Nos2 induction, in agreement with previous studies $[35,36]$. Moreover, butyrate reduces nitric oxide production, COX-2, and IL-6 induction and modulates inflammatory adipokines, such as LCN2 and NUCB2.

Recently, we demonstrated the beneficial effect of butyrate in a mice model of dietinduced obesity, not only on the weight loss, but also restoring adipokine dysfunction, and reducing inflammation [15]. Interestingly, adipokine dysregulation is a clear component of metabolic-triggered inflammation in $\mathrm{OA}$ and RA [30,37]. For instance, our group recently demonstrated that lipocalin-2 was implicated in human and murine chondrocyte pathophysiology, being it highly expressed in hypertrophic cells $[28,38]$. LCN2 is modulated by several factors, including IL-1 $\beta$, and increased in different rheumatic diseases [28]. It has been demonstrated that the human neutrophil gelatinase-associated lipocalin can contribute to cartilage matrix degradation in OA, by protecting MMP-9 activity [39]. Similarly, another novel adipokine, NUCB2, is involved in rheumatic disorders, in cartilage maturation and in the complex mechanisms of chondrocyte development and differentiation, with strong metabolic actions similar to those exerted by other members of adipokine superfamily [40]. Here, butyrate dampened the IL-1 $\beta$-induced increase of LCN2 and NUCB2, showing its ability to modulate the adipokine network also in inflamed chondrocytes.

During inflammation, adhesion molecules, whose expression is mainly regulated by inflammatory cytokines, facilitate the recruitment of circulating leukocytes to the sites of damage $[41,42]$. In severe OA, high levels of soluble VCAM-1 were linked to the risk of hip and knee joint replacement [26]. Our data show that, in IL-1 $\beta$-challenged chondrocytes, the expression of VCAM-1 and ICAM-1 was strongly decreased by butyrate, confirming its antiinflammatory effect in limiting leukocyte recruitment.

In articular chondrocytes, IL-1 $\beta$ was able to trigger MAPKinases signalling pathways, which in turn may lead to NF- $\kappa$ B and AP- 1 activation in the synovium of patients with RA and OA [43]. Hence, we investigated the effect of butyrate on the PI3-kinase/Akt pathway, whose inhibition blocks the activation of other convergent or downstream pathways, including ERK/MAPKinase [44]. Our data indicate that butyrate could modulate the intracellular inflammatory signalling in damaged cartilage, inhibiting IL-1 $\beta$-induced Akt activation and MAPK signalling.

It has been also demonstrated that IL-1 $\beta$ and hydrogen peroxide caused the activation of the redox-dependent transcription of NF- $\mathrm{KB}$ and AP-1 in bovine chondrocytes [45]. This effect triggers a remarkable decrease in type II collagen transcription, associated with a significant increase in MMP synthesis [45], leading to the onset of cartilage structural damage. Moreover, Terkeltaub et al. [46] showed that IL-1 $\beta$ and TNF $\alpha$ induced the expression of important metalloproteinases, such as MMP-3 and MMP-13. IL-1 $\beta$ stimulation induced a marked increase of MMP13 and the reduction of type II collagen in both undifferentiated and differentiated chondrocytes. These modifications were strongly counteracted by butyrate, highlighting, in addition to the anti-inflammatory effect, its capability in limiting extracellular matrix disruption and consequentially in reducing the loss of collagen, an important structural protein of healthy cartilage.

As known, the inflammatory response promotes the increased release of chemokines, which, acting as chemoattractants, guide cells toward the site of injury. Among these, fractalkine, or Cx3cl1, was significantly elevated in patients with knee OA [47]. Furthermore, these chemokines in $\mathrm{OA}$ patients might contribute to the unbalance between anabolism and catabolism of cartilage and chondrocytes [27, 48]. Interestingly, we observed that chemokine release by different inflammatory challenges was further increased by butyrate 


\section{Cellular Physiology Cell Physiol Biochem 2018;51:228-243 \begin{tabular}{ll|l} 
and Biochemistry & DOl: 10.1159/000495203 & $\begin{array}{l}\text { O } 2018 \text { The Author(s). Published by S. Karger AG, Basel } \\
\text { www.karger.com/cpb }\end{array}$
\end{tabular} \\ Pirozzi et al.: Butyrate Effect on Inflamed Chondrocytes}

treatment. This result suggests a potential contribution of butyrate in the inflammatory resolution. The resolution process is mediated by several factors, including AnxA1 [49]. Recent data demonstrated the positive correlation between HDACs inhibitors and the anti-inflammatory and pro-resolving AnxA1 [50]. Defective inflammation resolution or its dysregulation is involved in several chronic inflammatory disease including arthritis, asthma and cardiovascular disease [51]. Emerging evidence indicate that unbalance between specialized pro-resolving and pro-inflammatory mediators are associated with several human diseases. However, mechanisms that drive this unbalance remain largely unknown. In some cases, AnxA1 is up-regulated in human blood and tissues but fail to engage in proresolving signalling and, hence, to regulate excessive inflammation [52]. Our data show an increase of AnxA1 induced by butyrate, suggesting a likely role for this molecule in promoting the resolution of inflammation, reducing the unbalance between pro-inflammatory and anti-inflammatory mediators. These effects of butyrate have been also confirmed in totally differentiated ATDC5 cells after 14 days of cell differentiation, showing that the efficacy of butyrate does not depend on chondrocyte differentiation status. Interestingly, it has been demonstrated that these differentiated cells have a phenotype identical to human mature chondrocytes $[28,29]$.

Another novelty of this study was to determine the involvement of butyrate GPR43 receptor in chondrocyte IL-1 $\beta$-induced inflammation and chemotaxis. Actually, butyrate completely fails in chemokine and AnxA1 induction after GPR43 gene silencing. Previous studies demonstrated the relevant in vitro and in vivo role of GPR43 on immune cells and on SCFA-induced neutrophil chemotaxis [22]. This is the first time that GPR43 has been described as target of butyrate activity in chondrocytes. Moreover, after GPR43 silencing, butyrate was unable to reduce NOS type II and IL-6, strengthening the involvement of this receptor in butyrate modulation of chemotactic factors as well as inflammatory mediators. However, the involvement of other butyrate receptors or alternative molecular mechanisms in the effects of butyrate cannot be excluded.

\section{Conclusion}

In conclusion, our data define a novel GPR43-mediated anti-inflammatory mechanism of butyrate in chondrocytes. Butyrate reduced pro-inflammatory mediators, adhesion molecules and inhibited novel OA-linked inflammatory adipokines. All these effects are correlated with the inhibition of the most important inflammatory signalling pathways (i.e. NF- $\kappa$ B, ERK/MAPKinase, PI3kinase/Akt, AMPK). Butyrate also could promote the maintenance of cartilage integrity and homeostasis, limiting extracellular matrix disruption and the loss of type II collagen. Finally, we demonstrated the essential role of GPR43 in butyrate activity. The efficacy of this endogenous molecule in reducing inflammation in chondrocytes together with its chemoattractant effect may suggest its potential systemic or local application as multi-target approach for the management of chondrocyte inflammation, mainly responsible for cartilage degeneration in $\mathrm{OA}$.

\section{Acknowledgements}

Claudio Pirozzi, Oreste Gualillo and Rosaria Meli designed and conceived the research design; Claudio Pirozzi, Vera Francisco and Francesca Di Guida performed and conducted the experiments; Claudio Pirozzi, Rodolfo Gomez, Francisca Lago, Rosaria Meli and Oreste Gualillo analyzed the data, Claudio Pirozzi, Francisca Lago, Rosaria Meli and Oreste Gualillo wrote, reviewed and edited the manuscript. All the authors read and approved the final manuscript. 


\section{Cellular Physiology Cell Physiol Biochem 2018;51:228-243 \begin{tabular}{ll|l} 
and Biochemistry Published online: 16 November 2018 & $\begin{array}{l}\text { (c) } 2018 \text { The Author(s). Published by S. Karger AG, Basel } \\
\text { www.karger.com/cpb }\end{array}$ \\
\hline
\end{tabular} \\ Pirozzi et al.: Butyrate Effect on Inflamed Chondrocytes}

\section{Disclosure Statement}

The authors declare to have no conflicts of interest.

\section{References}

$>1$ Loeser RF, Goldring SR, Scanzello CR, Goldring MB: Osteoarthritis: a disease of the joint as an organ. Arthritis Rheum 2012;64:1697-1707.

-2 Berenbaum F: Osteoarthritis as an inflammatory disease (osteoarthritis is not osteoarthrosis!). Osteoarthritis Cartilage 2013;21:16-21.

-3 Kapoor M, Martel-Pelletier J, Lajeunesse D, Pelletier JP, Fahmi H: Role of proinflammatory cytokines in the pathophysiology of osteoarthritis. Nat Rev Rheumatol 2011;7:33-42.

-4 Mao G, Wu P, Zhang Z, Zhang Z, Liao W, Li Y, Kang Y: MicroRNA-92a-3p Regulates Aggrecanase-1 and Aggrecanase-2 Expression in Chondrogenesis and IL-1beta-Induced Catabolism in Human Articular Chondrocytes. Cell Physiol Biochem 2017;44:38-52.

5 Chabane N, Zayed N, Afif H, Mfuna-Endam L, Benderdour M, Boileau C, Martel-Pelletier J, Pelletier JP, Duval N, Fahmi H: Histone deacetylase inhibitors suppress interleukin-1beta-induced nitric oxide and prostaglandin E2 production in human chondrocytes. Osteoarthritis Cartilage 2008;16:1267-1274.

6 Schaeffer HJ, Weber MJ: Mitogen-activated protein kinases: specific messages from ubiquitous messengers. Mol Cell Biol 1999;19:2435-2444.

7 Otero M, Gomez Reino JJ, Gualillo 0: Synergistic induction of nitric oxide synthase type II: in vitro effect of leptin and interferon-gamma in human chondrocytes and ATDC5 chondrogenic cells. Arthritis Rheum 2003;48:404-409.

8 Wang P, Guan PP, Guo C, Zhu F, Konstantopoulos K, Wang ZY: Fluid shear stress-induced osteoarthritis: roles of cyclooxygenase- 2 and its metabolic products in inducing the expression of proinflammatory cytokines and matrix metalloproteinases. FASEB J 2013;27:4664-4677.

-9 Bournia VK, Kitas G, Protogerou AD, Sfikakis PP: Impact of non-steroidal anti-inflammatory drugs on cardiovascular risk: Is it the same in osteoarthritis and rheumatoid arthritis? Mod Rheumatol 2016:1-11.

10 Li NG, Tang YP, Duan JA, Shi ZH: Matrix metalloproteinase inhibitors: a patent review (2011 - 2013). Expert Opin Ther Pat 2014;24:1039-1052.

11 Ameye LG, Chee WS: Osteoarthritis and nutrition. From nutraceuticals to functional foods: a systematic review of the scientific evidence. Arthritis Res Ther 2006;8:R127.

12 Arias C, Zambrano T, Abdalla DS, Salazar LA: Polyphenol-Related Epigenetic Modifications in Osteoarthritis: Current Therapeutic Perspectives. Curr Pharm Des 2016;22:6682-6693.

13 Hamer HM, Jonkers D, Venema K, Vanhoutvin S, Troost FJ, Brummer RJ: Review article: the role of butyrate on colonic function. Aliment Pharmacol Ther 2008;27:104-119.

14 Canani RB, Costanzo MD, Leone L, Pedata M, Meli R, Calignano A: Potential beneficial effects of butyrate in intestinal and extraintestinal diseases. World J Gastroenterol 2011;17:1519-1528.

15 Mollica MP, Raso GM, Cavaliere G, Trinchese G, De Filippo C, Aceto S, Prisco M, Pirozzi C, Di Guida F, Lama A, Crispino M, Tronino D, Di Vaio P, Canani RB, Calignano A, Meli R: Butyrate Regulates Liver Mitochondrial Function, Efficiency, and Dynamic, in Insulin Resistant Obese Mice. Diabetes 2017;66:db160924.

16 Mattace Raso G, Simeoli R, Russo R, Iacono A, Santoro A, Paciello O, Ferrante MC, Canani RB, Calignano A, Meli R: Effects of sodium butyrate and its synthetic amide derivative on liver inflammation and glucose tolerance in an animal model of steatosis induced by high fat diet. PLoS One 2013;8:e68626.

17 Simeoli R, Mattace Raso G, Pirozzi C, Lama A, Santoro A, Russo R, Montero-Melendez T, Berni Canani R, Calignano A, Perretti M, Meli R: An orally administered butyrate-releasing derivative reduces neutrophil recruitment and inflammation in dextran sulphate sodium-induced murine colitis. Br J Pharmacol 2017;174:1484-1496.

18 Russo R, De Caro C, Avagliano C, Cristiano C, La Rana G, Mattace Raso G, Berni Canani R, Meli R, Calignano A: Sodium butyrate and its synthetic amide derivative modulate nociceptive behaviors in mice. Pharmacol Res 2016;103:279-291. 


\section{Cellular Physiology Cell Physiol Biochem 2018;51:228-243 \begin{tabular}{l|l|l} 
and Biochemistry Published online: 16 November 2018 & $\begin{array}{l}\text { ( 2018 The Author(s). Published by S. Karger AG, Basel } \\
\text { www.karger.com/cpb }\end{array}$ \\
\hline
\end{tabular}}

Pirozzi et al.: Butyrate Effect on Inflamed Chondrocytes

19 Wedlake L, Slack N, Andreyev HJ, Whelan K: Fiber in the treatment and maintenance of inflammatory bowel disease: a systematic review of randomized controlled trials. Inflamm Bowel Dis 2014;20:576-586.

20 Luhrs H, Gerke T, Muller JG, Melcher R, Schauber J, Boxberge F, Scheppach W, Menzel T: Butyrate inhibits NF-kappaB activation in lamina propria macrophages of patients with ulcerative colitis. Scand J Gastroenterol 2002;37:458-466.

21 Meijer K, de Vos P, Priebe MG: Butyrate and other short-chain fatty acids as modulators of immunity: what relevance for health? Curr Opin Clin Nutr Metab Care 2010;13:715-721.

-22 Vinolo MA, Ferguson GJ, Kulkarni S, Damoulakis G, Anderson K, Bohlooly YM, Stephens L, Hawkins PT, Curi R: SCFAs induce mouse neutrophil chemotaxis through the GPR43 receptor. PLoS One 2011;6:e21205.

-23 Young DA, Lakey RL, Pennington CJ, Jones D, Kevorkian L, Edwards DR, Cawston TE, Clark IM: Histone deacetylase inhibitors modulate metalloproteinase gene expression in chondrocytes and block cartilage resorption. Arthritis Res Ther 2005;7:R503-512.

24 Gomez R, Lago F, Gomez-Reino JJ, Dieguez C, Gualillo 0: Expression and modulation of ghrelin O-acyltransferase in cultured chondrocytes. Arthritis Rheum 2009;60:1704-1709.

-25 Kato K, Tokuda H, Matsushima-Nishiwaki R, Natsume H, Kondo A, Ito Y, Kozawa O, Otsuka T: AMPK limits IL-1-stimulated IL-6 synthesis in osteoblasts: involvement of IkappaB/NF-kappaB pathway. Cell Signal 2012;24:1706-1712.

-26 Schett G, Kiechl S, Bonora E, Zwerina J, Mayr A, Axmann R, Weger S, Oberhollenzer F, Lorenzini R, Willeit J: Vascular cell adhesion molecule 1 as a predictor of severe osteoarthritis of the hip and knee joints. Arthritis Rheum 2009;60:2381-2389.

27 Goldring MB, Otero M, Tsuchimochi K, Ijiri K, Li Y: Defining the roles of inflammatory and anabolic cytokines in cartilage metabolism. Ann Rheum Dis 2008;67 Suppl 3:iii75-82.

-28 Conde J, Gomez R, Bianco G, Scotece M, Lear P, Dieguez C, Gomez-Reino J, Lago F, Gualillo O: Expanding the adipokine network in cartilage: identification and regulation of novel factors in human and murine chondrocytes. Ann Rheum Dis 2011;70:551-559.

29 Santoro A, Conde J, Scotece M, Abella V, Lopez V, Pino J, Gomez R, Gomez-Reino JJ, Gualillo O: Choosing the right chondrocyte cell line: Focus on nitric oxide. J Orthop Res 2015;33:1784-1788.

-30 Abella V, Scotece M, Conde J, Pino J, Gonzalez-Gay MA, Gomez-Reino JJ, Mera A, Lago F, Gomez R, Gualillo 0 : Leptin in the interplay of inflammation, metabolism and immune system disorders. Nat Rev Rheumatol 2017;13:100-109.

31 Goldring MB: The role of the chondrocyte in osteoarthritis. Arthritis Rheum 2000;43:1916-1926.

-32 Cleophas MC, Crisan TO, Lemmers H, Toenhake-Dijkstra H, Fossati G, Jansen TL, Dinarello CA, Netea MG, Joosten LA: Suppression of monosodium urate crystal-induced cytokine production by butyrate is mediated by the inhibition of class I histone deacetylases. Ann Rheum Dis 2016;75:593-600.

-33 Takahashi T, Nagai H, Seki H, Fukuda M: Relationship between joint effusion, joint pain, and protein levels in joint lavage fluid of patients with internal derangement and osteoarthritis of the temporomandibular joint. J Oral Maxillofac Surg 1999;57:1187-1193; discussion 1193-1184.

-34 Pelletier JP, Martel-Pelletier J, Abramson SB: Osteoarthritis, an inflammatory disease: potential implication for the selection of new therapeutic targets. Arthritis Rheum 2001;44:1237-1247.

-35 Akhtar N, Haqqi TM: Epigallocatechin-3-gallate suppresses the global interleukin-1beta-induced inflammatory response in human chondrocytes. Arthritis Res Ther 2011;13:R93.

-36 Cheng AW, Stabler TV, Bolognesi M, Kraus VB: Selenomethionine inhibits IL-1beta inducible nitric oxide synthase (iNOS) and cyclooxygenase 2 (COX2) expression in primary human chondrocytes. Osteoarthritis Cartilage 2011;19:118-125.

-37 Abella V, Scotece M, Conde J, Gomez R, Lois A, Pino J, Gomez-Reino JJ, Lago F, Mobasheri A, Gualillo 0: The potential of lipocalin-2/NGAL as biomarker for inflammatory and metabolic diseases. Biomarkers 2015;20:565-571.

-38 Katano M, Okamoto K, Arito M, Kawakami Y, Kurokawa MS, Suematsu N, Shimada S, Nakamura H, Xiang Y, Masuko K, Nishioka K, Yudoh K, Kato T: Implication of granulocyte-macrophage colony-stimulating factor induced neutrophil gelatinase-associated lipocalin in pathogenesis of rheumatoid arthritis revealed by proteome analysis. Arthritis Res Ther 2009;11:R3.

-39 Gupta K, Shukla M, Cowland JB, Malemud CJ, Haqqi TM: Neutrophil gelatinase-associated lipocalin is expressed in osteoarthritis and forms a complex with matrix metalloproteinase 9. Arthritis Rheum 2007;56:3326-3335. 


\section{Cellular Physiology Cell Physiol Biochem 2018;51:228-243

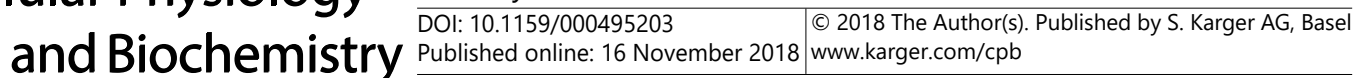 \\ Pirozzi et al.: Butyrate Effect on Inflamed Chondrocytes}

40 Scotece M, Conde J, Abella V, Lopez V, Lago F, Pino J, Gomez-Reino JJ, Gualillo O: NUCB2/nesfatin-1: a new adipokine expressed in human and murine chondrocytes with pro-inflammatory properties, an in vitro study. J Orthop Res 2014;32:653-660.

41 Ley K, Laudanna C, Cybulsky MI, Nourshargh S: Getting to the site of inflammation: the leukocyte adhesion cascade updated. Nat Rev Immunol 2007;7:678-689.

$\$ 42$ Lozhkin A, Vendrov AE, Pan H, Wickline SA, Madamanchi NR, Runge MS: NADPH oxidase 4 regulates vascular inflammation in aging and atherosclerosis. J Mol Cell Cardiol 2017;102:10-21.

\$3 Martin G, Bogdanowicz P, Domagala F, Ficheux H, Pujol JP: Rhein inhibits interleukin-1 beta-induced activation of MEK/ERK pathway and DNA binding of NF-kappa B and AP-1 in chondrocytes cultured in hypoxia: a potential mechanism for its disease-modifying effect in osteoarthritis. Inflammation 2003;27:233-246.

44 Grandage VL, Gale RE, Linch DC, Khwaja A: PI3-kinase/Akt is constitutively active in primary acute myeloid leukaemia cells and regulates survival and chemoresistance via NF-kappaB, Mapkinase and p53 pathways. Leukemia 2005;19:586-594.

45 Martin G, Andriamanalijaona R, Mathy-Hartert M, Henrotin Y, Pujol JP: Comparative effects of IL-1beta and hydrogen peroxide (H2O2) on catabolic and anabolic gene expression in juvenile bovine chondrocytes. Osteoarthritis Cartilage 2005;13:915-924.

46 Terkeltaub R, Yang B, Lotz M, Liu-Bryan R: Chondrocyte AMP-activated protein kinase activity suppresses matrix degradation responses to proinflammatory cytokines interleukin-1beta and tumor necrosis factor alpha. Arthritis Rheum 2011;63:1928-1937.

47 Zou Y, Li Y, Lu L, Lin Y, Liang W, Su Z, Wang X, Yang H, Wang J, Yu C, Huo L, Ye Y: Correlation of fractalkine concentrations in serum and synovial fluid with the radiographic severity of knee osteoarthritis. Ann Clin Biochem 2013;50:571-575.

48 Manferdini C, Maumus M, Gabusi E, Paolella F, Grassi F, Jorgensen C, Fleury-Cappellesso S, Noel D, Lisignoli G: Lack of anti-inflammatory and anti-catabolic effects on basal inflamed osteoarthritic chondrocytes or synoviocytes by adipose stem cell-conditioned medium. Osteoarthritis Cartilage 2015;23:2045-2057.

49 Perretti M, D'Acquisto F: Annexin A1 and glucocorticoids as effectors of the resolution of inflammation. Nat Rev Immunol 2009;9:62-70.

50 Montero-Melendez T, Dalli J, Perretti M: Gene expression signature-based approach identifies a proresolving mechanism of action for histone deacetylase inhibitors. Cell Death Differ 2013;20:567-575.

51 Fredman G, Tabas I: Boosting Inflammation Resolution in Atherosclerosis: The Next Frontier for Therapy. Am J Pathol 2017;187:1211-1221.

52 Perucci LO, Sugimoto MA, Gomes KB, Dusse LM, Teixeira MM, Sousa LP: Annexin A1 and specialized proresolving lipid mediators: promoting resolution as a therapeutic strategy in human inflammatory diseases. Expert Opin Ther Targets 2017;21:879-896. 